\title{
RESEARCH ON DURABILITY OF MAGNESIUM CEMENT REINFORCED CONCRETE IN A VARIETY OF FACTORS AND EXPERIMENTAL CONDITION OF BITTERN EROSION
}

\author{
Hongxia Qiao $^{1}$, Ndahirwa Desire ${ }^{2}$, Feng Qiong ${ }^{3}$, Cao Hui ${ }^{4}$ \\ ${ }^{1}$ Key Laboratory of Disaster Prevention and Mitigation in Civil Engineering of Gansu Province, \\ Lanzhou University of Technology, Lanzhou 730050, China \\ ${ }^{2}$ School of civil engineering and literature school of international education, Lanzhou University of Technology \\ ${ }^{3}$ Key Laboratory of Disaster Prevention and Mitigation in Civil Engineering of Gansu Province, \\ Lanzhou University of Technology, Lanzhou 730050, China \\ ${ }^{4}$ Key Laboratory of Disaster Prevention and Mitigation in Civil Engineering of Gansu Province, \\ Lanzhou University of Technology, Lanzhou 730050, China
}

\begin{abstract}
Aiming at the durability problem of magnesium cement reinforced concrete beams under the action of multiple factors in Chaerhan salt lake area in Golmud city, Qinghai province. This paper outlines a comprehensive experimental investigation about the durability of magnesium cement reinforced concrete beams under multiple factors effect through mass, relative quality and elastic modulus. Multiple factor tests conditions were carried out including test of bittern erosion, dry-wet cycle and freeze-thaw cycle. The results demonstrate that after wet-dry cycle and bittern erosion tests, freeze-thaw cycles from 0 to 180 cycles have little effect on the deterioration of concrete specimens. In 180 to 270 freeze-thaw cycles tests, magnesium cement reinforced concrete beam specimen's performance degraded continuously and eventually the beam's component was close to failure simultaneously the reinforcement corrosion was also very serious. In accordance with experimental analysis, magnesium cement concrete demonstrates a proficient performance when it is exposed to bittern erosion, dry-wet cycle and freeze-thaw cycle.
\end{abstract}

Keywords: Magnesium cement reinforced concrete; bittern erosion; dry-wet cycle; freeze-thaw cycle; durability

\section{INTRODUCTION}

Chaerhan salt lake is inland dry lake which is located in south eastern part of qaidam basin in Qinghai, with a total area of $5856 \mathrm{~km}^{2}$. It is a typical chloride type salt lake and is also known as the China's largest salt lake. At the same time, it is also one of the most famous interior salt lakes in the world. Currently, Chinese government is vigorously developing the use of these salt lake resources. In fact, it has invested in construction of a large number of buildings, which greatly increased the use of concrete in salt lake zone. Native and foreign scholars pay more attention to research on durability of concrete based on a variety of single factors furthermore; the study has delivered a lot of results however it cannot accurately reflect the actual conditions of concrete under the multiple factors - . Magnesium cement compared to ordinary Portland cement has many significant advantages, such as fast hardening and high mechanical strength and strong resistance to bittern erosion etc... nevertheless magnesium cement products have constraints of its wide range of applications disadvantages for example poor water resistance.

At present, the research work of magnesium cement reinforced concrete members is relatively lower. The application of magnesium cement is mostly limited to nonload-bearing components. Could or could not magnesium cement concrete be introduced in the field of load-bearing structures; this is the main focus of current study. Based on the requirement of the research and development of corrosion-resistant concrete in western salt lake area, if magnesium cement, sand and gravel could be combined together, their cooperative work with steel bar surface coating treatments in the structural members can lead to a new era of building materials production.

\section{EXPERIMENTAL PROGRAM}

\subsection{Chemical Properties}

When magnesium is in its metal form it can burn very easily in air. However, in order to start the reaction the magnesium metal needs a source of energy. When the magnesium metal burns it reacts with oxygen found in the air to form magnesium oxide.

$$
2 \mathrm{Mg}+\mathrm{O}_{2} \rightarrow 2 \mathrm{MgO}\left(600-650^{\circ} \mathrm{C},\right. \text { burning on air) }
$$

After it burns, it forms a white powder of the magnesium oxide. Magnesium gives up two electrons to oxygen atoms to form this powdery product. This is an exothermic reaction. 
$\mathrm{Mg}$ is oxidized and $\mathrm{Cl}$ is reduced to $\mathrm{Cl}^{-}$ions by accepting electrons, this kind of reaction is called an oxidationreduction (redox) reaction.

$$
\mathrm{Mg}+\mathrm{Cl}_{2} \text { (moisture) } \rightarrow \mathrm{MgCl}_{2} \text { (ambient temperature) }
$$

The acidity of $\mathrm{HCl}$ is been neutralized by $\mathrm{MgO}$ due to neutralization reaction.

$$
\mathrm{MgO}+2 \mathrm{HCl} \text { (diluted) } \rightarrow \mathrm{MgCl}_{2}+\mathrm{H}_{2} \mathrm{O}
$$

$\mathrm{MgCl}_{2} \cdot 6 \mathrm{H}_{2} \mathrm{O} \rightarrow \mathrm{MgCl}_{2}+6 \mathrm{H}_{2} \mathrm{O}\left(100-200^{\circ} \mathrm{C}\right.$, in stream of $\mathrm{HCl})$

\subsection{Materials and Mix Proportions}

Light burning magnesium oxide $(\mathrm{MgO})$ after determination of activity of $60 \%$ (shown in Table 1); industrial magnesium chloride $\left(\mathrm{MgCl}_{2}\right)$ in a crystalline state at ambient temperature, of the chloride magnesium hexahydrate formula $\mathrm{MgCl}_{2} \cdot 6 \mathrm{H}_{2} \mathrm{O}$, white, flaky (shown in Table 2); super plasticizer using KD naphthalene super plasticizer; fly ash of class I made in Lanzhou, the products of combustion in a power plant, iron-gray powder, specific gravity of 1.65 (shown in Table 3).

Table 1: Chemical composition of light calcined magnesia

\begin{tabular}{|l|l|l|l|}
\hline $\mathrm{MgO}$ & $\mathrm{CaO}$ & $\mathrm{Fe}$ & Others \\
\hline 90 & 2.5 & 1.0 & 6.5 \\
\hline
\end{tabular}

Table 2: Chemical composition of industrial magnesium chloride (mass ratio, \%)

\begin{tabular}{|l|l|l|l|l|}
\hline $\mathrm{MgCl}_{2} \cdot 6 \mathrm{H}_{2} \mathrm{O}$ & $\mathrm{SO}_{4}{ }^{2-}$ & $\mathrm{K}+\mathrm{Na}$ & $\mathrm{CaCl}_{2}$ & others \\
\hline 97 & 0.2 & 0.7 & 0.2 & 1.9 \\
\hline
\end{tabular}

Table 3: Chemical composition of pulverized fuel ash (mass

\begin{tabular}{|l|l|l|l|l|l|l|}
\hline $\mathrm{Fe}$ & $\mathrm{SiO}_{2}$ & $\mathrm{Al}_{2} \mathrm{O}_{3}$ & $\mathrm{CaO}$ & $\mathrm{TiO}_{2}$ & $\mathrm{~S}$ & $\mathrm{P}$ \\
\hline 11.20 & 40.50 & 22.90 & 2.37 & 1.43 & 0.15 & 0.076 \\
\hline
\end{tabular}

Coarse aggregate stone (fine stone) is related to continuous gradation, with qualified performance indicators. Gravel, fine aggregate grading is continuous and is classified in medium sand II area. Magnesium chloride solution and water are used in the laboratory bittern solution using distilled water. Reinforcement are HPB235, fy $=210$
$\mathrm{N} / \mathrm{mm}^{2}$, the longitudinal reinforced by $10 \mathrm{~mm}$ diameter thread steel bar, stirrup used light round bar diameter is 6 $\mathrm{mm}$.

\subsection{Experimental Methods}

At first, magnesium cement reinforced concrete beam specimen of size $500 \mathrm{~mm} \times 100 \mathrm{~mm} \times 75 \mathrm{~mm}$ was prepared; and next, that specimen was putted in bittern solution and immerse for $54 \mathrm{~h}$, afterward the electric hot fan was used to blow the specimen for $6 \mathrm{~h}$, so that the surface temperature of the specimen could vary between $40{ }^{\circ} \mathrm{C} \sim 50{ }^{\circ} \mathrm{C}$, after a while the specimen was putted in air cooling and standing for $12 \mathrm{~h}$ up to $72 \mathrm{~h}$ as a dry-wet cycle (cumulative $3 \mathrm{~d}$ ). The mass and relative elastic modulus of the specimen was measured every 20 cycles. In order to accelerate the destruction of concrete, freeze-thaw cycles were added into all specimens; each freeze-thaw cycle time is about $3 \mathrm{~h}$ and as the result in the specimen appears a slight damage; after every 15 times, the mass of a specimen and relative dynamic elastic modulus were determined until in the specimen appears more serious damage.

The compounding ratio and grouping numbers used in the specimens are shown in Table 4 and Table 5. The immersing solution is mainly made of sodium chloride and sodium sulfate (shown in Table 6).

Table 4: Mixing proportion of magnesium cement reinforced concrete

\begin{tabular}{|l|l|l|l|l|l|l|}
\hline $\begin{array}{l}\text { Mg } \\
\text { O }\end{array}$ & $\begin{array}{l}\text { Plasticiz } \\
\text { er }\end{array}$ & $\begin{array}{l}\text { Fly } \\
\text { ash }\end{array}$ & $\begin{array}{l}\text { San } \\
\text { d }\end{array}$ & $\begin{array}{l}\text { Ston } \\
\text { e }\end{array}$ & $\begin{array}{l}\text { MgCl } \\
\text { 2(L) }\end{array}$ & $\begin{array}{l}\text { Slump }(m) \\
\text { m) }\end{array}$ \\
\hline$(\mathrm{kg})$ & $\begin{array}{l}1.1 \\
4\end{array}$ & 14.2 & 21.2 & 3.9 & 45 \\
\hline 6.3 & 1.14 & \begin{tabular}{l}
1.9 \\
\hline
\end{tabular}
\end{tabular}

Table 5 Grouping and numbering of magnesium cement reinforced concrete

\begin{tabular}{|l|l|}
\hline $\begin{array}{l}\text { Experimental } \\
\text { condition }\end{array}$ & Specimen number \\
\hline $\begin{array}{l}\text { laboratory } \\
\text { wet and dry } \begin{array}{l}\text { cycle } \\
\text { cyce-thaw } \\
\text { freeze-th } \\
\text { cycles }\end{array}\end{array}$ & GSDR1 \\
\cline { 2 - 2 } & GSDR2 \\
\cline { 2 - 2 } & GSDR3 \\
\hline
\end{tabular}

Table 6: Main corrosive ions of chaerhan salt lake $(\mathrm{mg} / \mathrm{l})$

\begin{tabular}{|l|l|l|l|l|l|l|l|l|l|l|}
\hline element & total $\left(10^{3}\right)$ & $\mathrm{Na}^{+}$ & $\mathrm{K}^{+}$ & $\mathrm{Mg}^{2+}$ & $\mathrm{Ca}^{2+}$ & $\mathrm{Cl}^{-}$ & $\mathrm{SO}_{4}{ }^{2-}$ & $\mathrm{HCO}_{3}{ }^{-}$ & $\mathrm{CO}_{3}{ }^{2-}$ & $\mathrm{PH}^{-1}$ \\
\hline $\max$ & 555.06 & 108200 & 16610 & 94420 & 51860 & 365080 & 37440 & 470 & 1480 & 7.90 \\
\hline min & 50 & 270 & 20 & 2110 & 140 & 124360 & 20 & 120 & 130 & 4.60 \\
\hline average & 321.3 & 68360.5 & 5977.78 & 35129.7 & 4241 & 204209 & 22290 & 127.4 & 171.6 & 6.89 \\
\hline
\end{tabular}


3. TEST RESULTS AND ANALYSIS AFTER BITTERN EROSION, DRY AND WET CYCLES AND FREEZE-THAW CYCLES

\subsection{Selection of Evaluation Indexes and Parameter}

In this process, the curve of the relative mass and relative dynamic elastic modulus was measured. The relative mass and relative dynamic modulus of elasticity evaluation parameters $\left(\omega_{1}, \omega_{2}\right)$ were used as concrete durability evaluation $1,2,3,4,5$.

Based on the corresponding norms and combined with the natural characteristics of Golmud, considering the practical condition of test operation and laboratory, and finally taking into account the operability of the test, relative mass evaluation parameter $\left(\omega_{1}\right)$, relative dynamic modulus of elasticity evaluation parameter $\left(\omega_{2}\right)$ and relative dynamic modulus of elasticity $\left(E_{\mathrm{r}}\right)$ were selected as durability evaluation parameter of concrete.
The following formulas:

$$
\omega_{1}=\left(\mathrm{W}_{\mathrm{r}}-0.95\right) / 0.05
$$

Where $\mathrm{W}_{\mathrm{r}}$ is the relative mass.

$$
{ }_{2}=\left(\begin{array}{ll}
E_{r} & 0.6
\end{array}\right) / 0.40
$$

According to the standard for test methods of long-term performance and durability of ordinary concrete (GB/T 50082-2009), the relation between ultrasonic velocity and relative dynamic modulus $\left(E_{r}\right)$ can be expressed as:

$$
E_{\mathrm{r}}=\frac{E_{\mathrm{t}}}{E_{0}}=\frac{v_{\mathrm{t}}^{2}}{v_{0}^{2}}
$$

Where E0 is the initial dynamic elastic modulus, $E_{t}$ is the dynamic elastic modulus at time $(t), v_{0}$ is the initial ultrasonic velocity, vt is the ultrasonic velocity at time $(\mathrm{t})$.

\subsection{Results and Analysis of Relative Mass Evaluation Parameters}

\subsubsection{Relative Mass Evaluation Parameters after Wet and Dry Cycle}

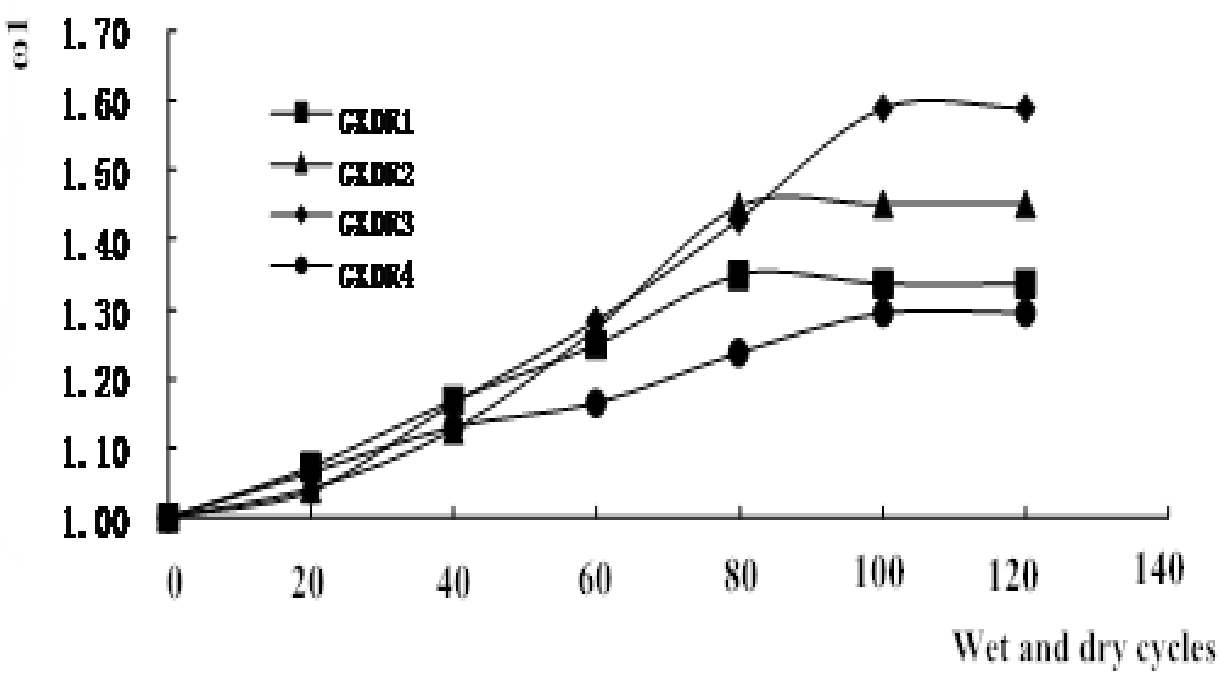

Fig.1: Evaluation parameters $\left(\omega_{1}\right)$ under dry-wet circulation

As it can be seen from the graph, in the interval of times 40 to 60 wet and dry cycles $\omega_{1}$ of GXDR3 has sharply increased compared to DXDR4 which has a low rate of increase. From 80 to 100 times of wet and dry cycles, $\omega_{1}$ for GXDR1 and GXDR2 has decreased while for GXDR3 and GXDR4 $\omega_{1}$ was still gradually increasing. From 100 and 120 times of wet and dry cycles, the value of $\omega_{1}$ remained constant to all specimens.

Briefly, the relative mass evaluation parameter $\omega_{1}$ of the specimens has been gradually increased up to 80 times of dry and wet cycle (shown in Fig.1). After a certain number of cycles, it is observed that the growth rate decreases. The specimen, after several times of wet and dry cycle, due to bittern erosion and wet and dry effects, the destruction of spalling is more serious, so the trend of increasing mass is getting smaller and smaller, and ultimately no longer increase, and began to tend to reduce small trend ${ }^{7}$.

3.2.2 Relative Mass Evaluation Parameters during 0-180 Cycles of Freeze-Thaw Cycles 
After 120 times of wet and dry cycle, the relative mass evaluation parameters $\left(\omega_{1}\right)$ of the specimens are larger than the reference value (shown in Fig.2), and its value also shows an increasing trend, indicating that the overall performance of the component also is within the normal range. So, freeze-thaw cycles were added in order to accelerate the destruction of concrete ${ }^{8}$.

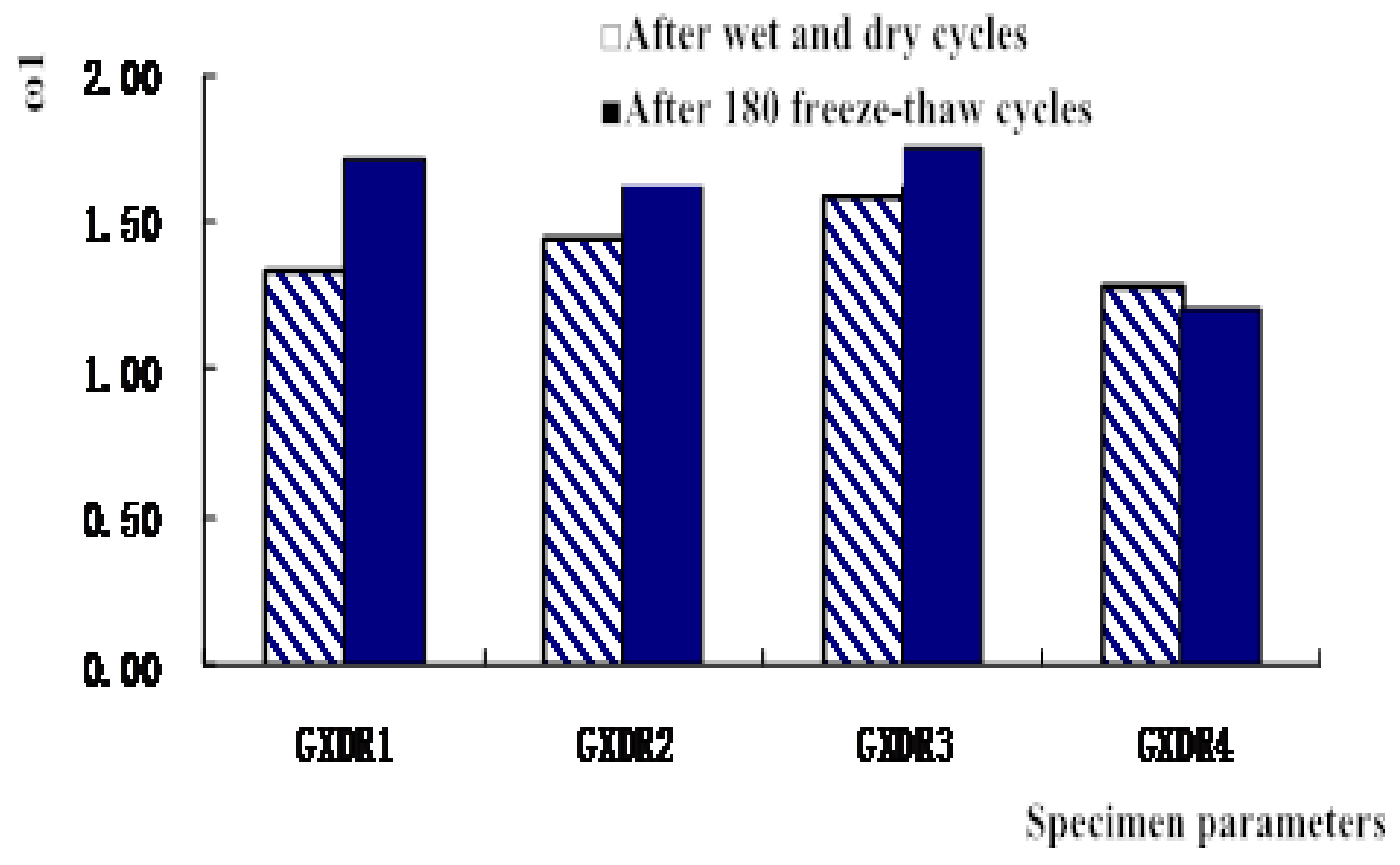

Fig. 2: Evaluation parameters $\left(\omega_{1}\right)$ after dry-wet circulation and freezing-thawing cycle

As shown in Fig.2, it can be observed that the values of the relative mass evaluation parameters $\left(\omega_{1}\right)$ of the specimens GXDR1, GXDR2, GXDR3 gradually increased compared with the end of dry-wet cycle and only GXDR4 slightly decreased. 


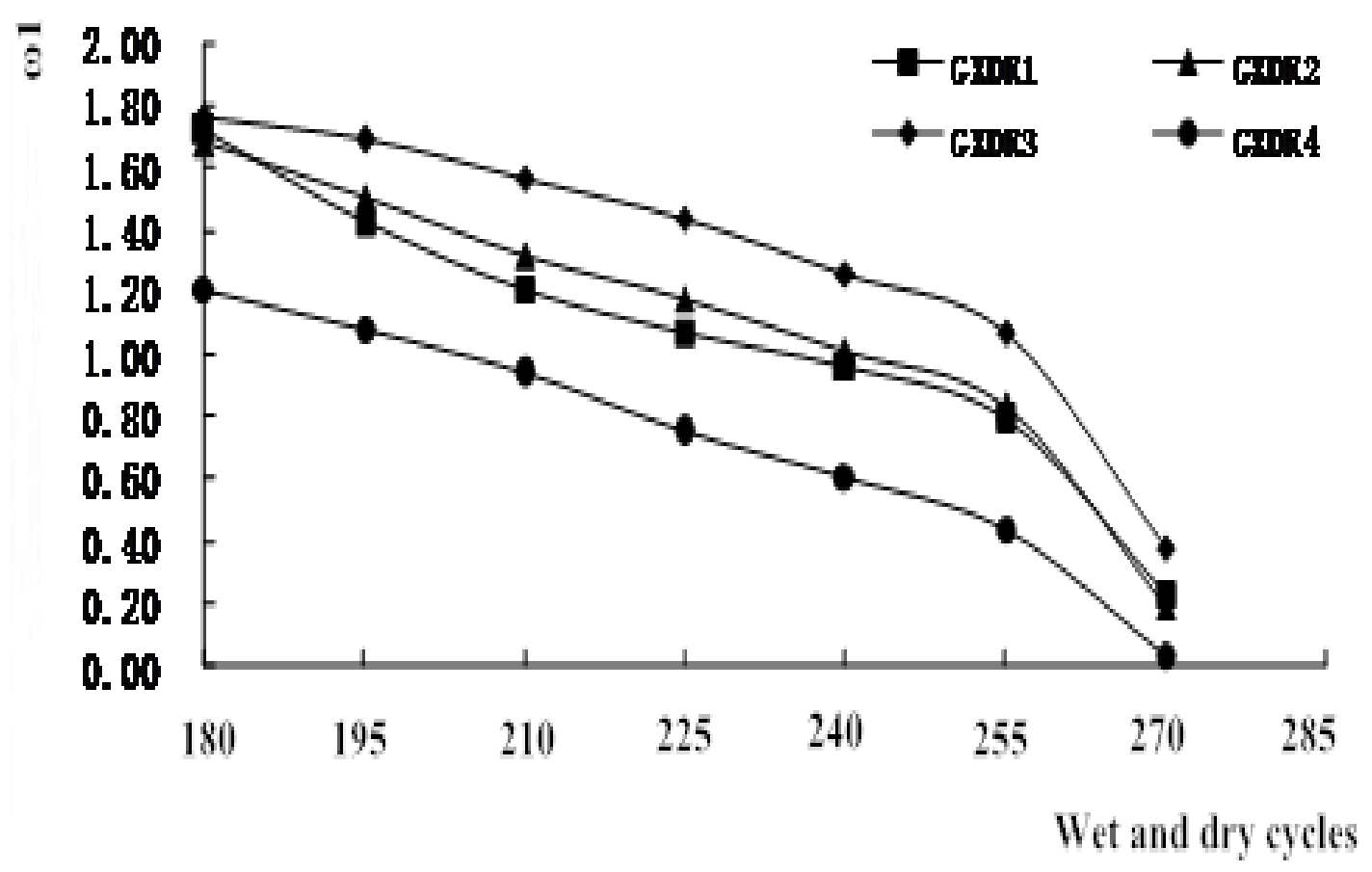

Fig. 3: Evaluation parameters $\left(\omega_{1}\right)$ after dry-wet circulation

\subsubsection{Relative Mass Evaluation Parameters during}

\section{0-270 Cycles of Freeze-Thaw Cycles}

The values of the GXDR1, GXDR2, GXDR3 and GXDR4 (shown in Fig.3) were slowly decreased during the 180 to 255 freeze-thaw cycles. During the freeze-thaw cycles of 255 to 270 , the values were sharply decreased. Since the $\omega_{1}$ of the GXDR4 specimen has been about zero, the freezethaw cycle is stopped ${ }^{10}$.

\subsection{Results and Analysis of the Relative Dynamic}

\section{Elastic Modulus Evaluation Parameters}

\subsubsection{Relative Dynamic Elastic Modulus Evaluation}

Parameters during Wet and Dry Cycle

(1) Relative dynamic elastic modulus in the longitudinal direction $(500 \mathrm{~mm})$

As shown in Fig. 4, from 0 to 60 times of wet and dry cycles, $\omega_{2}$ of all specimens has been continuously increasing, and from 60 to 100 times of wet and dry cycles, $\omega_{2}$ for all the specimens has sharply increased, however from 100 to 120 times of wet and dry cycles, $\omega_{2}$ has decreased. Briefly, it can be concluded that after wettingdrying cycles, in the longitudinal direction, relative dynamic elastic modulus evaluation parameters $\omega_{2}$ has been greater than one, and showed the increasing trend at first and then decreasing trend. 


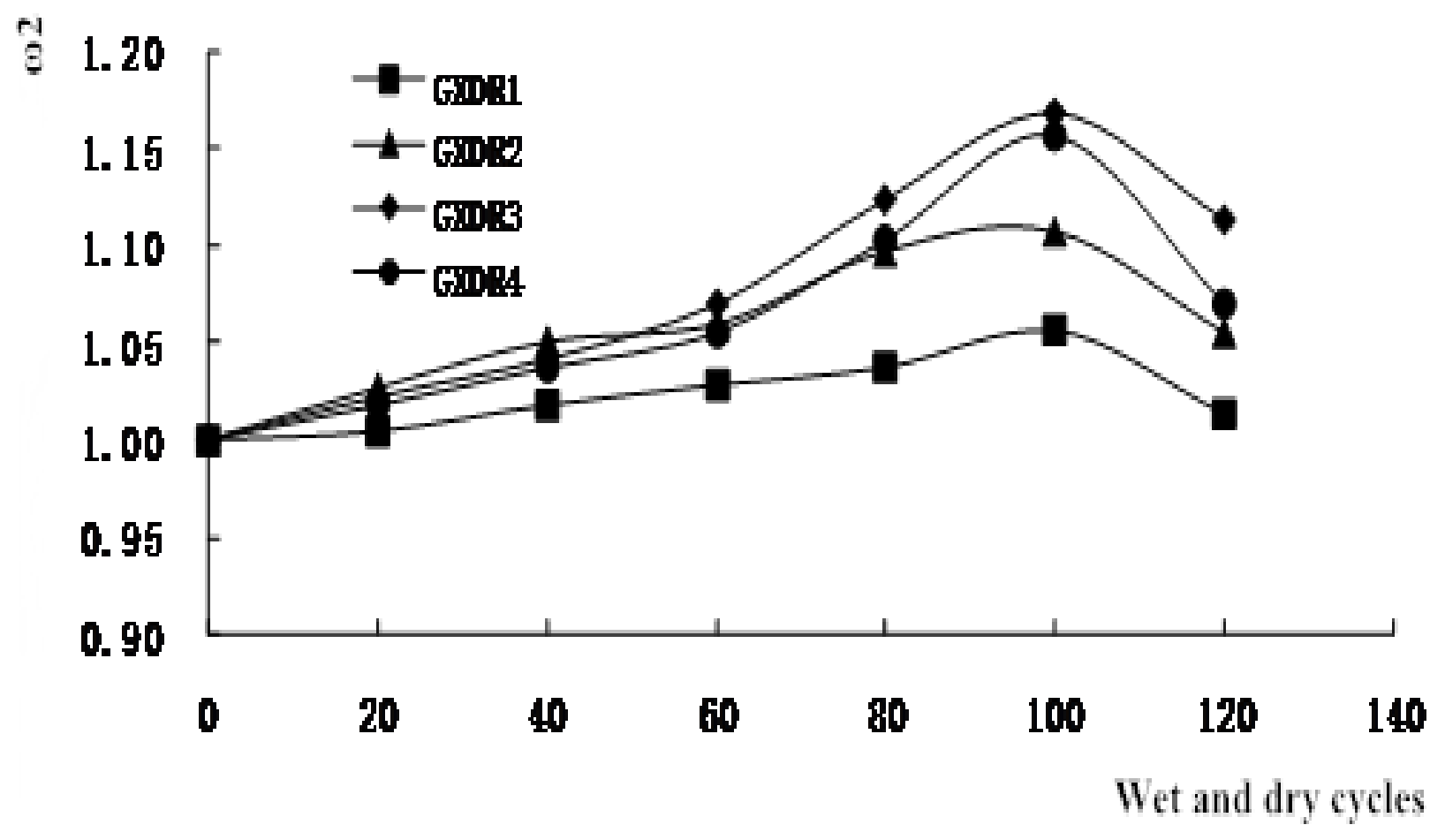

Fig. 4: Relative dynamic modulus of elasticity $\left(\omega_{2}\right)$ across the length after dry-wet circulation

(2) Relative dynamic elastic modulus in width direction (75mm)

Relative dynamic elastic modulus the evaluation parameters $\omega_{2}$ have the same trend with the length direction (shown in Figure 5) in the width direction.

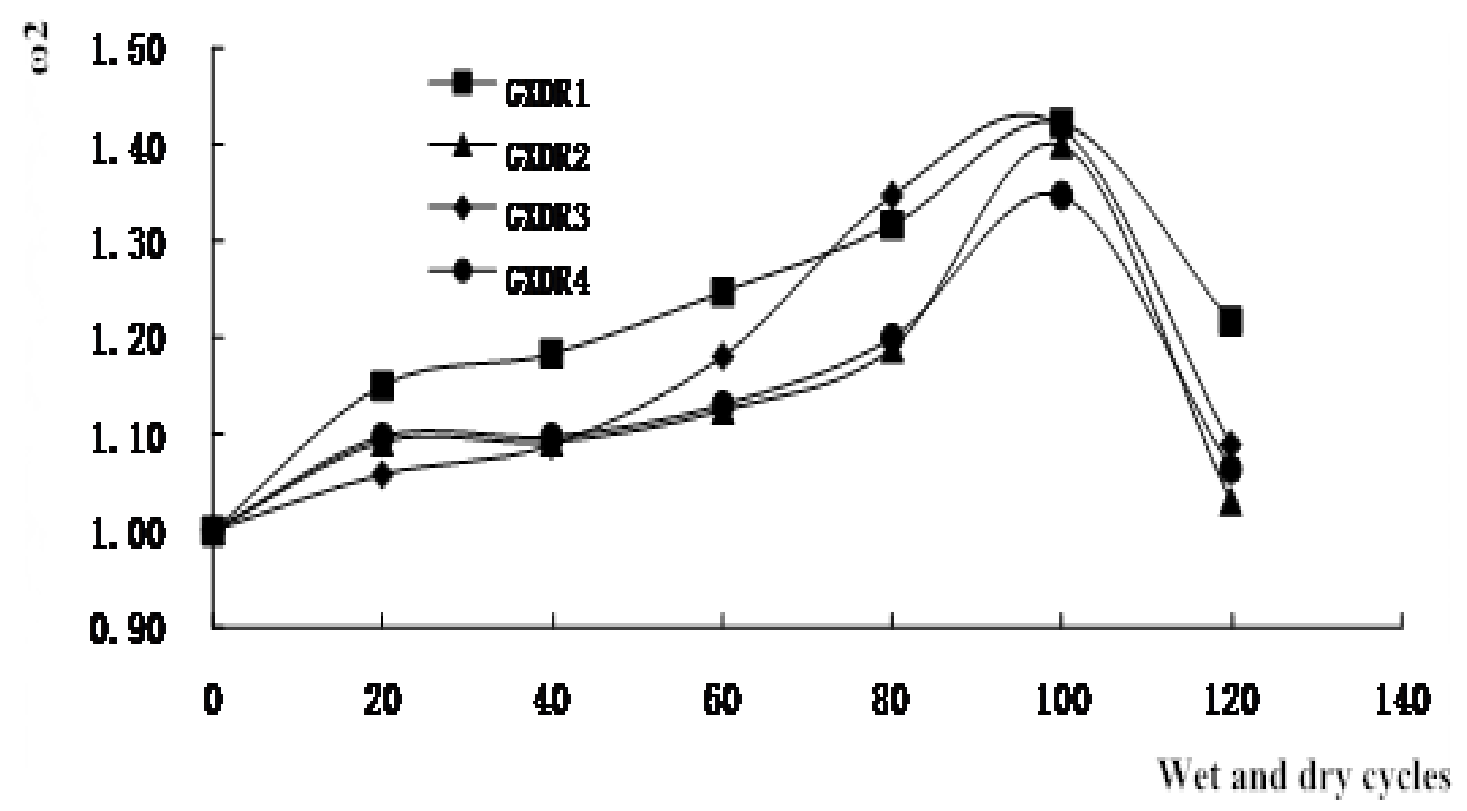

Fig. 5: Relative dynamic modulus of elasticity $\left(\omega_{2}\right)$ across the width after dry-wet circulation

Throughout the wet and dry cycle (shown in Fig.4, 5), overall trends of the values of relative dynamic modulus of elasticity $\omega_{2}$ are increasing at 0 to 100 cycles. After 100 cycles, it is decreased. It indicates that performance of 
concrete begins to deteriorate, after 100 wetting-drying cycles, the relative dynamic elastic modulus gradually decreases.

After 120 dry and wet cycles relative dynamic elastic modulus evaluation parameters of all specimens are larger than the reference value, and its value has also been a growing tendency before 100 cycles, after the end of 100 cycles begin to decline, the concrete begins a slight deterioration. In order to accelerate the destruction of concrete, freeze-thaw cycles were added into all specimens.

\subsubsection{The Relative Dynamic Elastic Modulus Evaluation Parameters after 0-180 Cycles of Freeze-Thaw Cycles}

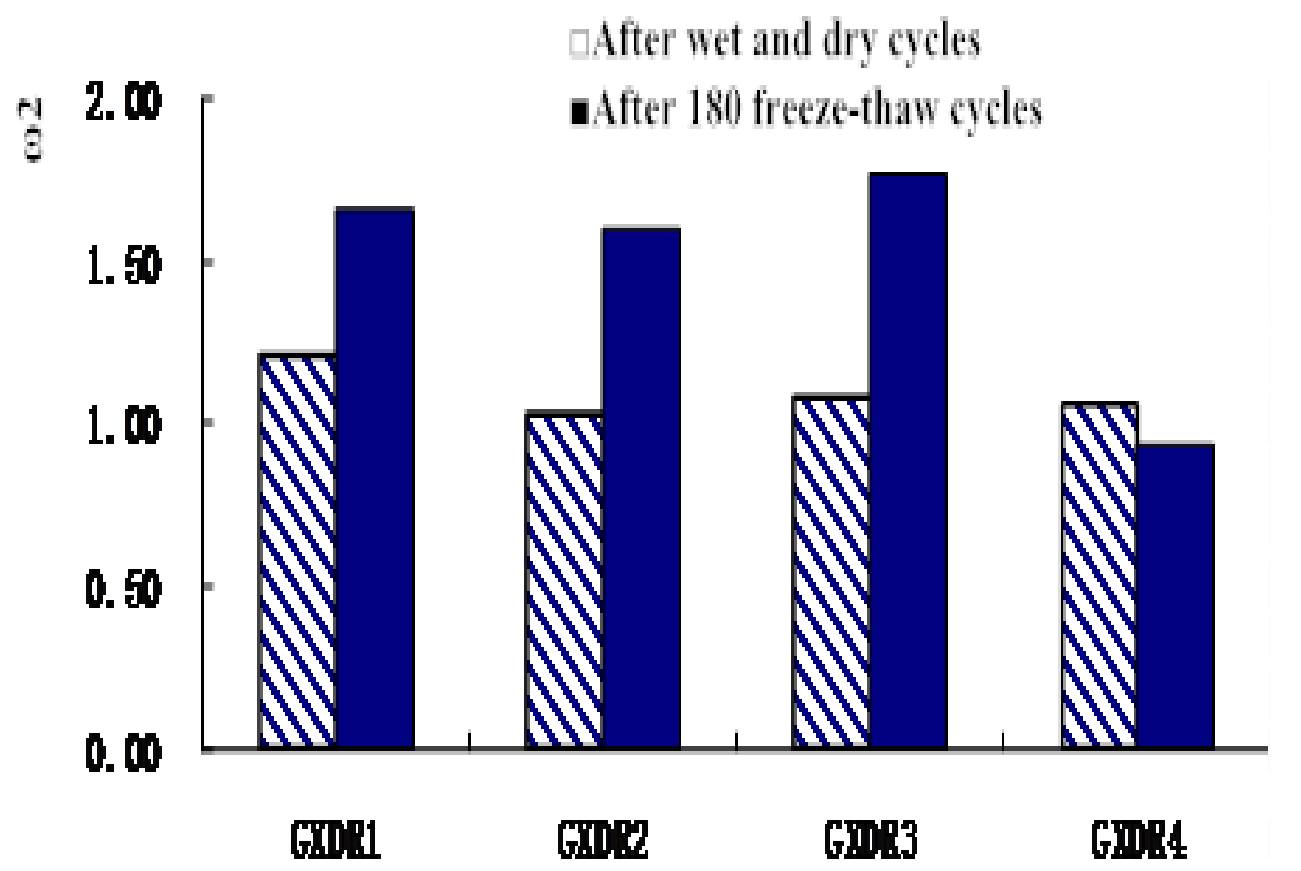

\section{Specimen parameters}

Fig. 6: Evaluation parameters $\left(\omega_{2}\right)$ after dry-wet circulation and freezing and thawing cycle

At the end of the wet and dry cycle (shown in Fig.6), the relative dynamic modulus of the specimens GXDR1, GXDR2, GXDR3 and GXDR4 evaluates the value of the parameter $\omega_{2}$, after 180 cycles of freezing and thawing ,only the value of GXDR4 has been decreased, the other three values have increased.

\subsubsection{The Relative Dynamic Elastic Modulus Evaluation Parameters during 180-270 Cycles of Freeze-Thaw Cycles}

The values of the relative dynamic elastic modulus evaluation parameters $\omega_{2}$ are continuously decreasing during the freeze-thaw cycle (shown in Fig.7) in the interval of 180 to 270 cycles, indicating that the deterioration of the concrete is becoming more and more serious. To 270 cycles, the relative dynamic elastic modulus of each specimen evaluation parameters $\omega_{2}$ values are about zero, and the concrete failure occurs. 


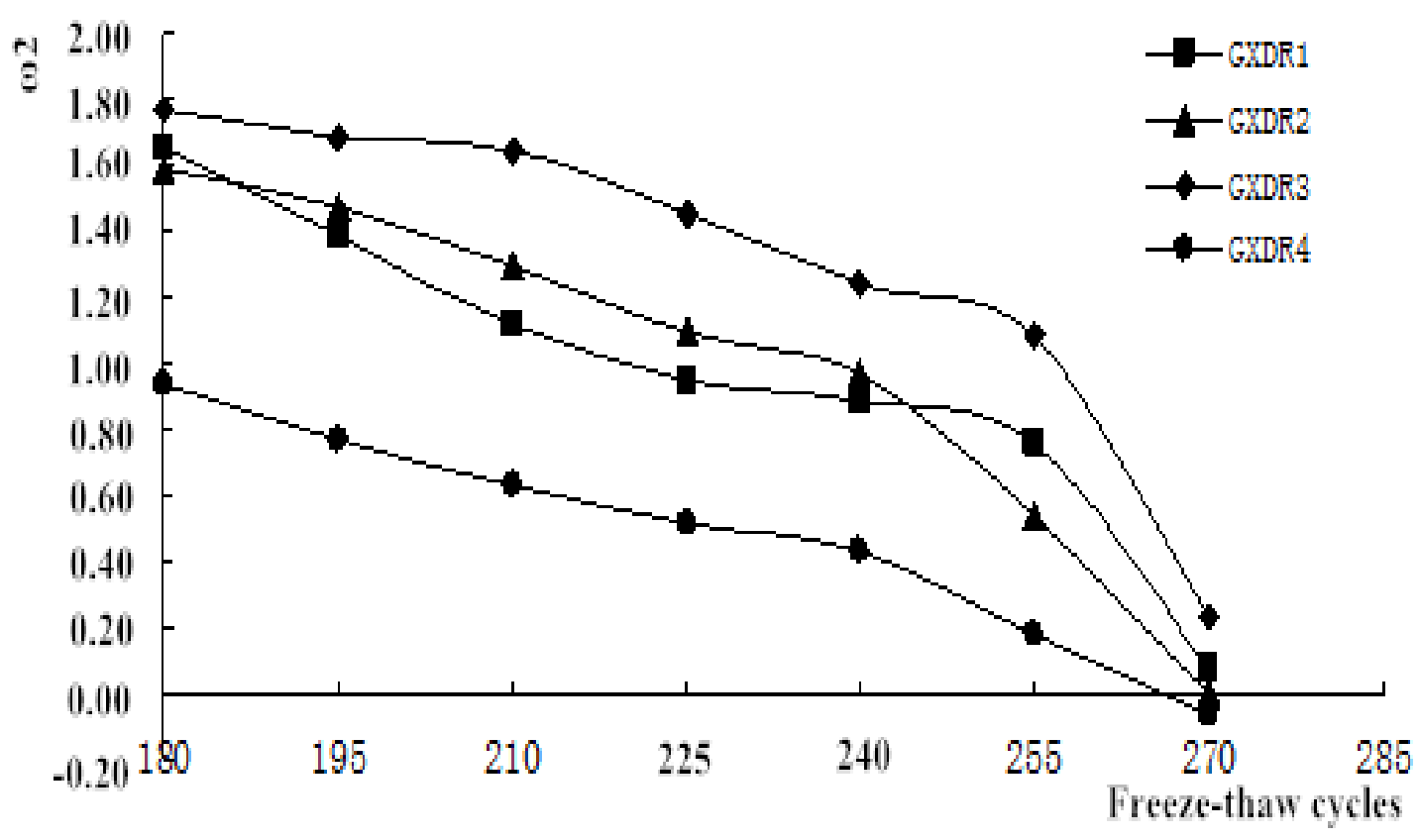

Fig 7: Evaluation parameters $\left(\omega_{2}\right)$ after freezing-thawing cycle

The relative dynamic elastic modulus evaluation parameters of GXDR2 and GXDR4 after 240 cycles of freeze and thaw cycles of GXDR2 and GXDR4 were decreased sharply, and when the value drop down to around 0 at the end of 270 freeze-thaw cycles concrete has been damaged. As result of the end of the test, magnesium cement reinforced concrete beam specimens have been occurring more serious corrosion, there is no need of its short-term loading and steel corrosion test.

\section{CONCLUSION}

(1). After 120 times of wet-dry cycle process, indicating that magnesium cement reinforced concrete beam specimen in the first 100 times during the wet and dry cycle performance continues to strengthen, after 100 times its performance is no longer enhanced.

(2). After 180 times freeze-thaw cycle accelerated test, indicating that the performance of magnesium cement reinforced concrete beam specimen is still strengthening and also the resistance to bittern erosion is very strong.

(3). During 180 to 270 times freeze-thaw cycle process, indicating that magnesium cement reinforced concrete beam specimens continue to deteriorate, and ultimately near to failure state. The durability of magnesium cement concrete in salt lake area is effective and its resistance to bittern erosion is prominent.

\section{ACKNOWLEDGEMENT}

Supported by National Natural Science Foundation of China (No. 51168031 and 51468039).

\section{REFERENCES}

[1] Hong-xia qiao. The durability of concrete resistance to sulfate corrosion evaluation method research [D] [lanzhou university of technology, Ph.D. Thesis]. Lanzhou, 2007, 130-132.

[2] Hong-xia qiao, Zhou Mingru zhong-mao he, etc., for example, the performance of concrete in sulfate environment study $[\mathrm{J}]$. Applied basic and engineering science journal, 2009 (1):77-84.

[3] Zhang Yui-xue ZhangWeiping.Introduction to the durability of concrete structure [M]. Shanghai science and technology publishing house, 2003:128-130.

[4] Niu Di tao. The concreted structure durability and life prediction [M]. Beijing: science press, 2003, 164-167.

[5] Deng D.Zhang C. The formation mechanism of the hydrate phases in magnesium oxychloride cements [J]. Cem Concr Res, 1999, 29 (9) : 1365-1371.

[6] Sorrel C.A, Armstrong C.R. Reactions and equilibria in magnesium oxychloride cements $[\mathrm{J}]$. J Am Ceram Soc, 1976, 59 (1-2) : 51-59.

[7] Matkovic B., Popovic S.and Rogic V., et al. Reaction and Equilibria in Magnesium Oxychloride Cement Pastes System MgO-MgCl2-H2O[J]. J Am Ceram Soc, 1977, 60 (11-12) : 504-507.

[8] ying-zi wang, Qiu Zhenxin, wang xiang. Introduction to the performance of magnesium oxychloride cement products and development $[\mathrm{J}]$. Journal of shandong building materials, 2000, (4):38-40.

[9] Yan Yutong, Jing Yan, Ma jun. The research progress of magnesium oxychloride cements [J]. Journal of salt lake research, 2008 (3):60-66.

[10] Yu Hongfa,SunWei, Wang Jiachun etc. Salt lake region of environmental conditions and the durability 
of concrete and reinforced concrete structure $[\mathrm{J}]$. Industrial construction, 2003, 33 (3):-4, 10.

[11] Yu Hongfa. Bittern corrosion resistance of research present situation and the development direction of the cement concrete $[\mathrm{J}]$. Journal of silicate, 1999, 27 (4): 237-245.

[12] Liu Lianxin. Chaerhan salt lake and saline soil region of concrete erosion and prevention study [J]. Journal of building materials, 2001, 4 (4):5-400.

[13] Feldman R.F. and Cheng-yi H., Resistance of mortars containing silica fume to attack by a solution containing chlorides [J], Cem. Concr. Res., 1985, 15: 411-420.

[14] YuHongfa, SunWei, Wang Jiachun etc. Salt lake region long-term corrosion products and corrosion mechanism of concrete $[\mathrm{J}]$. Journal of silicate, 2003, Vol. 31, No. 5:434-440

[15] han-wen zhang. Chaerhan salt lake brine erosion problems of cement concrete $[\mathrm{J}]$. Proceedings of China building materials research institute, 1984, (1):15-26.

[16] Wang Panlao Zhang Weiqin, Yang Youkun etc. Chaerhan salt lake of qinghai region corrosion and damage investigation and analysis of cement concrete [J]. Journal of qinghai university, 2003, 21 (6): 57-59. 